\title{
Computational Fluid Dynamics Modeling of Proton Exchange Membrane Fuel Cells
}

\author{
Sukkee Um and C.Y. Wang ${ }^{1}$ \\ GATE Center for Advanced Energy Storage \\ Department of Mechanical Engineering \\ The Pennsylvania State University \\ University Park, PA 16802 \\ K.S. Chen' \\ Engineering Sciences Center \\ Sandia National Laboratories \\ Albuquerque, NM 87185-0834 \\ A manuscript to be submitted to \\ Journal of Electrochemical Society

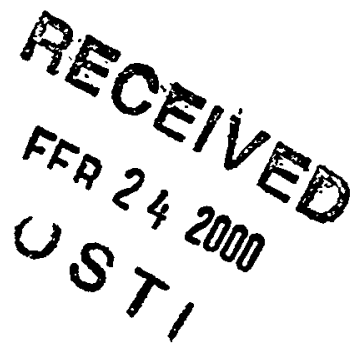 \\ as a technical paper
}

Electrochemical Society Active Member 


\section{DISCLAIMER}

This report was prepared as an account of work sponsored by an agency of the United States Government. Neither the United States Government nor any agency thereof, nor any of their employees, make any warranty, express or implied, or assumes any legal liability or responsibility for the accuracy, completeness, or usefuiness of any information, apparatus, product, or process disclosed, or represents that its use would not infringe privately owned rights. Reference herein to any specific commercial product, process, or service by trade name, trademark, manufacturer, or otherwise does not necessarily constitute or imply its endorsement, recommendation, or favoring by the United States Government or any agency thereof. The views and opinions of authors expressed herein do not necessarily state or reflect those of the United States Government or any agency thereof. 


\section{DISCLAIMER}

Portions of this document may be illegible in electronic image products. Images are produced from the best available original document. 


\begin{abstract}
A transient, multi-dimensional model has been developed to simulate proton exchange membrane (PEM) fuel cells. The model accounts simultaneously for electrochemical kinetics, current distribution, hydrodynamics and multi-component transport. A single set of conservation equations valid for flow channels, gas-diffusion electrodes, catalyst layers and the membrane region are developed and numerically solved using a finite-volume-based computational fluid dynamics (CFD) technique. The numerical model is validated against published experimental data with good agreement. Subsequently, the model is applied to explore hydrogen dilution effects in the anode feed. ? The predicted polarization curves under hydrogen dilution conditions are found to be in qualitative agreement with recent experiments reported in the literature. The detailed two-dimensional electrochemical and flow/transport simulations further reveal that in the presence of hydrogen dilution in the fuel stream, hydrogen is depleted at the reaction surface resulting in substantial kinetic polarization and hence a lower current density that is limited by hydrogen transport from the fuel stream to the reaction site.
\end{abstract}




\section{Introduction}

Proton exchange membrane (PEM) fuel cell engines can potentially replace the internal combustion engine for transportation because they are clean, quiet, energyefficient, modular and capable of quick start-up. Since a PEM fuel cell simultaneously involves electrochemical reactions, current distribution, hydrodynamics, multicomponent transport and heat transfer, a comprehensive mathematical model is needed in order to gain a fundamental understanding of the interacting electrochemical and transport phenomena and to provide a computer-aided tool for design and optimization of future fuel cell engines.

Performance of a fuel cell is measured by its current-voltage relation (i.e. the polarization curve). At a particular current the voltage drop is mainly caused by: (1) overpotentials of electrochemical reactions (mainly on the cathode); (2) the ohmic drop across the ionomeric membrane; and (3) the mass transport limitations of reactants and products. At high current densities of special interest to vehicular applications, excessive water is produced within the air cathode in the form of liquid thus leading to a gas-liquid two-phase flow in the porous electrode. The ensuing two-phase transport of gaseous reactants to the reaction surface, i.e. the cathode/membrane interface, becomes a limiting mechanism for cell performance, particularly at high current densities (e.g. $>1 \mathrm{~A} / \mathrm{cm}^{2}$ ). On the anode side, when reformate is used for the feed gas, the incoming hydrogen stream is diluted with nitrogen and carbon dioxide. The effects of hydrogen dilution on anode performance, particularly under high fuel utilization conditions, are significant. ${ }^{1,2}$

Excellent reviews of the hydrogen PEM fuel cell research up to mid-1990s were presented by Prater ${ }^{3}$ and Gottesfeld. ${ }^{4}$ Modeling and computer simulation of hydrogen fuel 
cells have been attempted by a number of groups with the common goal of better understanding and hence optimizing fuel cell systems. Notable work includes those of Bernardi and Verbrugge ${ }^{5.6}$, Springer et al. ${ }^{7.8}$, Fuller and Newman ${ }^{9}$, Nguyen and White ${ }^{10}$, Garau et al. ${ }^{11}, \mathrm{Yi}$ and Nguyen ${ }^{12.13}$. Except for Garau et al. ${ }^{11}$ and $\mathrm{Yi}$ and Nguyen ${ }^{13}$, previous models are essentially one-dimensional or pseudo two-dimensional, assuming that fuel and oxidizer streams are well mixed and their compositions do not vary along the flow channels. While such models are useful for small single cells, their applicability to large-scale fuel cells, particularly under high fuel utilization conditions, is limited. Nevertheless, the one-dimensional models of Bernardi and Verbrugge ${ }^{5.6}$ and Springer et al. ${ }^{7,8}$ provided a fundamental framework to build multi-dimensional módels that followed. The pseudo two-dimensional models developed by Fuller and Newman ${ }^{9}$, Nguyen and White $^{10}$ and later Yi and Nguyen ${ }^{12}$ further demonstrated the important roles played by water and heat management in maintaining high performance of PEM fuel cells.

Most recently, Gurau et al. ${ }^{11}$ presented a two-dimensional model of transport phenomena in PEM fuel cells. This work illustrated the utility of a multi-dimensional model in the understanding of the internal conditions of a fuel cell such as the oxygen and water distributions. In a separate development, $\mathrm{Yi}$ and $\mathrm{Nguyen}^{13}$ formulated a twodimensional model to explore hydrodynamics and multi-component transport in the air cathode of PEM fuel cells with an interdigitated flow field. Recent efforts have also been made to model two-phase flow and transport in the air cathode, a critical issue that has repeatedly been emphasized in the literature for fuel cells operated under high current densities. ${ }^{1+, 15}$ 
The objective of the present study is two-fold. One is to develop a transient, multi-dimensional model for electrochemical kinetics, current distribution, fuel and oxidant flow, and multi-component transport in a realistic fuel cell based on a finitevolume-based computational fluid dynamics (CFD) approach. The CFD method was first adapted to electrochemical systems by Gu et al. ${ }^{16}$ and has since been applied successfully to a variety of battery systems including lead-acid, nickel-cadmium, nickel-metal hydride, lithium-ion, and the primary $\mathrm{Li} / \mathrm{SOCl}_{2}$ cell. ${ }^{16-22}$ The present work is intended to extend the efficient single-domain CFD formulation previously developed for batteries to PEM fuel cells. The second gqal, and also of practical importance, is to explore hydrogen dilution effects on PEM fuel cells running on reformate gas. Such effects were most recently investigated experimentally but have not been modeled.

The following section describes a transient, multi-dimensional mathematical model for electrochemical and transport processes occurring inside a PEM fụel cell. Model validation against the experimental data of Ticianelli et al. ${ }^{23}$ is presented in Section 3 along with a detailed, two-dimensional study of hydrogen dilution effects. The last section summarizes the major conclusions from this study and identifies further research based on the present CFD modeling framework.

\section{Numerical Model}

Figure 1 schematically shows a PEM fuel cell divided into seven sub-regions: the anode gas channel, gas-diffusion anode, anode catalyst layer, ionomeric membrane, cathode catalyst layer, gas-diffusion cathode, and cathode flow channel. Distinct from previous models, the present model considers the anode feed consisting of hydrogen, water vapor and nitrogen in order to simulate reformate gas, whereas humidified air is fed 
into the cathode channel. Hydrogen oxidation and oxygen reduction reactions are considered to occur only within the active catalyst layers where Pt/C catalysts are intermixed uniformly with recast ionomer. Other aspects of hydrogen fuel cell modeling can be found in the works of Bernardi and Verbrugge ${ }^{6}$ and Springer et al. ${ }^{8}$

The fuel and oxidant flow rates can be described by a stoichiometric flow ratio, $\zeta$, defined as the amount of reactant in the chamber gas feed divided by the amount required by the electrochemical reaction. That is,

$$
\begin{aligned}
& \zeta_{+}=X_{o 2}^{0} \vartheta_{+}^{0} \frac{p_{+}}{R T} \frac{4 F}{|I| A} \\
& \zeta_{-}=X_{H 2}^{0} \vartheta_{-}^{0} \frac{p_{-}}{R T} \frac{2 F}{|I| A}
\end{aligned}
$$

where $\vartheta^{0}$ is the inlet volumetric flow rate to a gas channel, $p$ and $T$ the pressure and temperature, $R$ and $F$ the universal gas constant and Faraday's constant, $I$ the current density, and $A$ the electrode surface area. The subscripts $(+)$ and $(-)$ denote the çathode and anode sides, respectively. For convenience, the stoichiometric flow ratios defined in Eqs.(1) and (2) are chosen to be based on the reference current density of $1 \mathrm{~A} / \mathrm{cm}^{2}$ in the present work so that the ratios can also be considered as dimensionless flow rates of the fuel and oxidant.

\section{Model Assumptions}

The present model assumes:

- incompressible and laminar flow;

- ideal gas mixtures;

- isotropic and homogeneous electrodes, catalyst layers and membrane;

- constant cell temperature; and 
- negligible potential drop in the electronically-conductive solid matrix of porous electrodes and catalyst layers as well as the current collectors.

\section{Governing Equations}

In contrast to the approach of Garau et al. "l which employs separate differential equations for different sub-regions, we take the single-domain approach used in our previous battery models in which a single set of governing equations valid for all subregions are used. As a result, no interfacial conditions are required to be specified at internal boundaries between 'various regions. In general, fuel cell operation under isothermal conditions is described by mass, momentum, species and charge conservation principles. Thus, under the above-mentioned assumptions, the model equations can be written, in the vector form, as ${ }^{19}$

$$
\begin{aligned}
& \frac{\partial(\varepsilon \rho)}{\partial t}+\nabla \cdot(\varepsilon \rho \vec{u})=0 . \\
& \frac{\partial(\varepsilon \rho \vec{u})}{\partial t}+\nabla \cdot(\varepsilon \rho \bar{u} \vec{u})=-\varepsilon \frac{\partial p}{\partial x}+\nabla \cdot\left(\varepsilon \mu^{e f f} \nabla \vec{u}\right)+S_{u} \\
& \frac{\partial\left(\varepsilon X_{k}\right)}{\partial t}+\nabla \cdot\left(\varepsilon \vec{u} X_{k}\right)=\nabla \cdot\left(D_{k}^{e f f} \nabla X_{k}\right)+S_{k} \\
& \nabla \cdot\left(\sigma_{e}^{e f f} \nabla \Phi_{e}\right)+S_{\Phi}=0
\end{aligned}
$$

In the above $\vec{u}, p, X_{k}$, and $\Phi_{e}$ denote the intrinsic fluid velocity vector, pressure, mole fraction of chemical species $k$ and the phase potential of the electrolyte membrane, respectively. The diffusion coefficient of species $\mathrm{k}$ and ionic conductivity of the membrane phase in Eqs.(5) and (6) are effective values modified via Bruggman correlation to account for the effects of porosity and tortuosity in porous electrodes, catalyst layers and the membrane. That is,

$$
D_{k}^{e f f}=\varepsilon_{s}^{1.5} D_{k}
$$




$$
\sigma_{e}^{\text {eff }}=\varepsilon_{s}^{1.5} \sigma_{e}
$$

where $\varepsilon_{s}$ is the volume fraction of solid membrane and other symbols in Eqs. (3) through (6) can be found in the Nomenclature section.

Notice that three source terms, $S_{u}, S_{k}$, and $S_{\Phi}$, appear in momentum, species and charge conservation equations to represent various volumetric sources or sinks arising from each sub-region of a fuel cell. Detailed expressions of these source terms are given in Table I. Specifically, the momentum source term is used to described Darcy's drag for flow through porous electrodes, active catalyst layers and the membrane. ${ }^{6.11 .16}$ In addition, electro-osmotic drag arising from the catalyst layers and the membrane is also included.

Generation or consumption of chemical species $k$ only occurs in the active catalyst layers where electrochemical reactions take place. So does the creation of electric current (see Table I). Both $S_{k}$ and $S_{\Phi}$ terms are therefore related to the transfer current between the solid matrix and the membrane phase inside each of the catalyst layers. These transfer currents at anode and cathode can be expressed as follows ${ }^{4}$ :

$$
\begin{aligned}
& j_{a}=a i_{0 a}^{\text {ref }} \cdot\left(\frac{X_{H 2}}{X_{H 2, \text { ref }}}\right)^{1 / 2} \cdot\left(\frac{\alpha_{a}+\alpha_{c}}{R T} \cdot F \cdot \eta\right) \\
& j_{c}=-a i_{0 c}^{\text {ref }} \cdot\left(\frac{X_{O 2}}{X_{O 2 . \text { ref }}}\right) \cdot \exp \left(-\frac{\alpha_{c} F}{R T} \cdot \eta\right)
\end{aligned}
$$

The above kinetics expressions are derived from the general Butler-Volmer equation based on the facts that the anode exhibits fast electrokinetics and hence a low surface overpotential to justify a linear kinetic rate equation, and that the cathode has relatively 
slow kinetics to be adequately described by Tafel equation. In Eqs.(9) and (10) the surface overpotential, $\eta(x, y)$, is defined as

$$
\eta(x, y)=\Phi_{s}-\Phi_{e}-V_{u c}
$$

where $\Phi_{s}$ and $\Phi_{e}$ stand for the potentials of the electronically-conductive solid matrix and electrolyte, respectively, at the electrode/electrolyte interface. $V_{v c}$ is the open-circuit potential of an electrode. It is equal to zero on the anode but is a function of temperature on the cathode ${ }^{24}$; namely

$$
V_{u c,+}=0.0025 * T+0.2329
$$

where $T$ is in Kevin and $V_{o c}$ in Volts. Under the assumption of a perfectly conductive solid matrix for electrodes and catalyst layers, $\Phi_{s}$ is equal to zero on the anode side at the anodic current collector and to the cell voltage on the cathode side at the cathodic current collector. Thus, the surface overpotential given by Eq.(11) is only dependent upon the membrane phase potential which is to be solved from Eq.(6).

The species diffusivity, $D_{k}$, varies in different sub-regions of the PEM fuel cell depending on the specific physical phase of component $k$. In flow channels and porous electrodes, species $\mathrm{k}$ exists in the gaseous phase and thus the diffusion coefficient takes the value in gas, whereas species $\mathrm{k}$ is dissolved in the membrane phase within the catalyst layers and the membrane, and thus takes the value corresponding to dissolved species, which is usually a few orders of magnitude lower than that in gas (see Table II). In addition, the diffusion coefficient is a function of temperature and pressure ${ }^{25}$, i.e.

$$
D(T)=D_{0}\left(\frac{T}{T_{0}}\right)^{3 / 2}\left(\frac{p_{0}}{p}\right)
$$


The proton conductivity in the membrane phase has been correlated by Springer et al. $^{7}$ as

$$
\sigma_{e}(T)=100 \cdot \exp \left[1268\left(\frac{1}{303}-\frac{1}{T}\right)\right] \cdot(0.005139 \lambda-0.00326) \quad \text { in } \mathrm{S} / \mathrm{cm}
$$

where the water content in the membrane, $\lambda$, depends on the water activity, $a$, according to the following fit of the experimental data:

$$
\lambda= \begin{cases}0.043+17.18 a-39.85 a^{2}+36.0 a^{3} & \text { for } 0<a \leq 1 \\ 14+1.4(a-1) & \text { for } 1 \leq a \leq 3\end{cases}
$$

The water activity is in turn calculated by

$$
\begin{aligned}
& \begin{aligned}
a= & \frac{X_{H 2 O} \cdot p}{p^{\text {sar }}}
\end{aligned} \\
& \text { the saturation pressure of water vapor can be computed from Spring } \\
& p^{\text {sat }}= \\
& \quad+2.1794+0.02953 \cdot(T-273.15)-9.1837 \cdot 10^{-5} \cdot(T-273.15)^{2} \\
&
\end{aligned}
$$

The above calculated saturation pressure is in bars.

For the present multi-component system, the general species transport equation given in Eq.(5) is applied to solve for mole fractions of hydrogen, oxygen, and water vapor. The mole fraction of nitrogen is then obtained by the following constraint:

$$
\begin{array}{ll}
X_{N 2}=1-X_{H 2}-X_{H 2 O} & \text { on the anode side } \\
X_{N 2}=1-X_{O 2}-X_{H 2 O} & \text { on the cathode side }
\end{array}
$$

Once the electrolyte phase potential are determined in the membrane, the local current density along the axial direction can be calculated as follows:

$$
I(y)=-\left.\sigma_{e}^{e f f} \frac{\partial \Phi}{\partial x}\right|_{x=I . F .}
$$


where I.F means the interface between the membrane and catalyst layer. The average current density is then determined by

$$
I_{\text {arg }}=\frac{1}{L} \int_{0}^{L} I(y) d y
$$

where $L$ is the cell length.

\section{Boundary Conditions}

Equations (3) through (6) form a complete set of governing equations for $(m+5)$ unknowns where $\mathrm{m}$ is the physical dimension of the problem: $\vec{u}, p, X_{H 2}, X_{O 2}, X_{H 2 O}$, and $\Phi_{e}$. Their boundary conditions are required only at the external surfaces of the computational domain due to the single-domain formulation used. These are no-flux conditions everywhere except for the inlets and outlets of the flow channels. At the fuel and oxidant inlets, the following conditions are prescribed:

$$
\begin{aligned}
& u_{\text {in.anowle }}=U_{-}^{0}, \quad u_{\text {in.cuthode }}=U_{+}^{0} \\
& X_{H 2 \text {.anode }}=X_{H 2,-}, \quad X_{O 2, \text { cathude }}=X_{O 2,+}, \quad X_{H 20 \text {.anode }}=X_{H 20 .-}, \quad X_{H 20 \text {.cathode }}=X_{H 20 .+}
\end{aligned}
$$

The inlet velocities of fuel and oxidant can also be expressed by their respective stoichiometric flow ratios, i.e. $\zeta$ and $\zeta_{+}$at $1 \mathrm{~A} / \mathrm{cm}^{2}$. At the outlets, both channels are assumed sufficiently long that velocity and species concentration fields are fully developed.

\section{Numerical Procedures}

The conservation equations, Eqs. (3) through (6), were discretized using a finite volume method ${ }^{26}$ and solved using a general-purpose computational fluid dynamic (CFD) code. Details of the numerical solution procedure and the code have been given in the 
previous work. ${ }^{16,18}$ A point worth mentioning here is that although some species are practically non-existing in certain regions of a fuel cell, the species transport equation can still be applied throughout the entire computational domain by using the large source term technique originally proposed by Voller. ${ }^{27}$ For example, there is virtually no hydrogen in the cathode catalyst layer, gas-diffusion cathode and cathode gas channel. Therefore, in these sub-regions, a sufficiently large source term is assigned to the hydrogen transport equation, which effectively 'freezes' the hydrogen mole fraction at zero.

Stringent numerical tęsts were performed to ensure that the solutions were independent of the grid size. It was found that a 35 by 90 mesh provides sufficient spatial resolution. The coupled set of equations were solved simultaneously, and the solution was considered to be convergent when the relative error in each field between two consecutive iterations was less than $10^{-5}$. A typical simulation involving approximately 22,000 unknowns required about 20 minutes of $\mathrm{CPU}$ time on a $600 \mathrm{MHz} \mathrm{PC}$.

\section{Results and Discussion}

\section{Experimental Validation}

To validate the numerical model presented in the preceding section, comparisons were made to the experimental data of Ticianelli et al. ${ }^{23}$ for a single cell operated at two different temperatures. The parameters used in the following simulations were taken from Bernardi and Verbrugge ${ }^{6}$ and are summarized in Table II.

Figure 2 compares the computed polarization curves with the measured ones. The calculated curves show good agreement with the experimental data for both temperatures. 
The product of the specific interfacial area and the exchange current density for the anodic reaction used in these simulations is so large that the predicted surface overpotential prevailing in the anode catalyst layer is practically negligible, which is in accordance with the experimental measurement.

While no data of velocity and concentration fields were provided in the experiments of Ticianelli et al. ${ }^{23}$, these detailed results can also be generated from the present model to shed light on the internal operation of the fuel cell. Figure 3 shows the predicted flow field inside the entire cell, and the water vapor and oxygen mole fraction fields within the porous cathode and its adjacent flow channel for the experimental fuel cell at $353 \mathrm{~K}$. It can be seen that the velocity exhibits parabolic profiles in both anode and cathode gas channels and reduces essentially to zero in the regions of porous structure. The water vapor mole fraction increases along the cathode gas chaninel while the mole fraction of oxygen decreases, due to the electrochemical reaction within the çathode catalyst layer where oxygen is reduced by protons migrating through the membrane from the anode side to produce water.

Figure 4 displays the local current density distributions at various average current densities along the axial direction of fuel cells. The current density distributions are quite uniform at all cell average current densities due probably to the small cell employed in these experiments.

In the present model it is assumed that water only exists in the vapor state. However, it should be noted that if the electrochemical reaction rate is sufficiently high, the amount of water produced would be condensed into the liquid phase. In this situation, two-phase flow and transport must be considered. Figure 5 displays water vapor 
mole fraction profiles along the interface between the catalyst layer and gas diffuser on the cathode side where there is the highest content of water vapor. It is evident that when the cell current density is higher than about $6000 \mathrm{~A} / \mathrm{m}^{2}$, the water vapor mole fraction along the catalyst layer/gas diffuser interface already exceeds the saturated level, i.e. $X_{H \geq 0}^{s a r}=0.093541$ at the pressure of $5 \mathrm{~atm}$ and the cell temperature of $353 \mathrm{~K}$. Hence, it appears that the two-phase flow regime already starts at intermediate current densities.

\section{Hydrogen Dilution Effects ,}

When reformate gas is used as the anode feed, the hydrogen mole fraction at the anode inlet is significantly lower than that in the pure hydrogen condition (i.e., hydrogen plus water vapor only). As a consequence, hydrogen dilution has a strong effect on the cell performance. A series of simulations for different hydrogen inlet fractions at the anode have been carried out to illustrate this effect. In all these simulations, the stoichiometric flow ratios of fuel and oxidant are 2.8 and 3.0 at $1 \mathrm{~A} / \mathrm{cm}^{2}$ respectively. It can be seen from Figures 6 and 7 that the cell current density at the cell voltage of $0.6 \mathrm{~V}$ decreases significantly as the inlet hydrogen content is lowered, particularly in the range below 50 percent. The cell polarization curves under pure and hydrogen dilution conditions are displayed in Figure 7, showing qualitatively good agreement with the most recent experiments of Rockward et al. ${ }^{1}$.

Figure 8 shows predicted profiles of the membrane phase potential across the anode catalyst layer, the membrane and the cathode catalyst layer at various axial locations. In the case of pure hydrogen, nearly zero overpotential is predicted within the anode catalyst layer, indicating that the hydrogen oxidation kinetics on the anode is much 
faster than the cathode reaction. Furthermore, the membrane phase potential profile remains similar at different axial locations. However, in the presence of large hydrogen dilution, the overpotential for the hydrogen oxidation within the anode catalyst layer significantly increases as the hydrogen mole fraction at the reaction surface is drastically reduced. This can easily be explained by Eq. (9) where the transfer current is proportional to the square root of the hydrogen mole fraction. Downstream along the gas channel, the anode gas is progressively depleted in hydrogen as it is consumed by the electrochemical reaction, and thus the overpotential required to sustain a particular current density becomes larger The $_{\text {The }}$ The also appreciable differences in the membrane phase potential profile at various locations along the channel. A limiting current density may occur when hydrogen is completely depleted at the reaction surface thus leading to an infinitely large anode polarization loss.

Figure 9 shows the two-dimensional contours of hydrogen mole fraction in the anode gas channel and porous electrode for $10 \%$ hydrogen dilution and no dilution cases, respectively. It is seen that under the hydrogen dilution condition, the hydrogen mole fraction decreases along the flow channel as well as across the porous anode. These trends are more apparent from Figure 10 which displays the hydrogen mole fraction profiles at several important boundaries. The 'down-the-channel'. effect becomes particularly significant in high fuel utilization conditions that are needed for the highest possible fuel efficiency. This effect can, however, be alleviated by using large fuel flow rates and thus at the expense of fuel utilization. For example, the 'down-the-channel' effect is not significant in the case displayed in Fig.10. The substantial drop of $\mathrm{H}_{2}$ mole fraction across the anode is caused by diffusion of hydrogen from the anode stream to the 
reaction surface, a limiting step for the cell current density in this case. On the contrary, the hydrogen supply from the fuel stream to the reaction surface appears adequate in the case of no dilution, as can be seen in Fig. $9 \mathrm{~b}$.

The above simulations provide a good illustration of the capabilities of the present model. Although the results for hydrogen dilution effects are shown to be realistic, more detailed analyses and parametric studies are desirable to fully investigate hydrogen dilution and high fuel utilization effects. This will be presented in the near future.

\section{Conclusion}

!

A single-domain formulation was developed to comprehensively describe electrochemical kinetics, current distribution, hydrodynamics, and multi-component transport in hydrogen PEM fuel cells. A finite-volume-based computational fluid dynamics technique was successfully adapted to simulate multi-dimensional behaviors of the fuel cell. The CFD model was shown to be able to predict not only the experimental polarization curves of Ticianelli et al. $^{23}$ but also the detailed reactant and product distributions inside the cell. In addition, the CFD model was used to understand the hydrogen dilution effect when the reformer gas is used as the anode feed. It was found that hydrogen dilution leads to a much lower cell current density that is limited by the diffusive transport of hydrogen to the reaction site.

The results presented here have focused only on the steady-state operation of PEM fuel cells. However, the present CFD model can also simulate the transient response of a fuel cell to dynamically varying operating conditions; these transient results will be reported in a separate publication. Efforts are also underway to simulate threedimensional behaviors of PEM fuel cells. 


\section{Acknowledgments}

This work was partially supported by Sandia National Laboratories. Sandia is a multiprogram laboratory operated by Sandia Corporation, a Lockheed Martin Company, for the United States Department of Energy under Contract DE-AC04-94AL85000. The work is also supported by NSF under Grant No. DUE-9979579.

\section{Nomenclature}

$A=$ superficial electrode area

$c=$ molar concentration, $\mathrm{mol} / \mathrm{m}^{3}$

$D=$ mass diffusivity of species, $\mathrm{m}^{2} / \mathrm{s}$

$I=$ current density, $A / m^{2}$ ?

$j=$ transfer current, $A / \mathrm{m}^{3}$

$p=$ pressure, $\mathrm{Pa}$

$R=$ gas constant, $8314 \mathrm{~J} / \dot{\mathrm{mol}} \cdot \mathrm{K}$

$S=$ Source term in transport equations

$t=$ time

$T$ = temperature, $K$

$\vec{u}=$ velocity vector, $m / s$

$U=$ inlet velocity, $\mathrm{m} / \mathrm{s}$

$V=$ cell potential, $\mathrm{V}$

$X=$ mole fraction of species

\section{Greek letters}

$\lambda=$ membrane water content, $\mathrm{mol} \mathrm{H}_{2} \mathrm{O} / \mathrm{mol} \mathrm{SO}_{3}^{-}$

$\Phi=$ phase potential, $\mathrm{V}$

$\eta=$ overpotential, $\mathrm{V}$

$\mu=$ viscosity, $\mathrm{kg} / \mathrm{m} \cdot \mathrm{s}$

$v=$ kinematic viscosity, $\mathrm{m}^{2} / \mathrm{s}$

$\vartheta=$ volumetric flow rate, $\mathrm{m}^{3} / \mathrm{s}$

$\rho=$ density, $\mathrm{kg} / \mathrm{m}^{3}$ 
$\sigma=$ ionic conductivity

$\zeta=$ stoichiometric flow ratio, Eq.(1)

\section{Superscripts}

$0=$ gas channel inlet value

eff $=$ effective value

sat $=$ saturation value

\section{Subscripts}

$$
\begin{aligned}
& \mathrm{a}=\text { anode } \\
& \mathrm{c}=\text { cathode } \\
& \mathrm{e}=\text { electrolyte } \\
& k=\text { species } \\
& \mathrm{m}=\text { membrane } \\
& \mathrm{oc}=\text { open circuit } \\
& \mathrm{ref}=\text { reference value } \\
& \mathrm{s}=\text { solid phase of electrode } \\
& u=\text { momentum equation } \\
& \phi=\text { potential equation } \\
& +=\text { cathode } \\
& -=\text { anode }
\end{aligned}
$$

\section{References}

1. T. Rockward, T. Zawodzinski, J. Bauman, F. Uribe, J. Valerio, T. Springer and S. Gottesfeld, Abstract No.566 in Meeting Abstracts of $195^{\text {th }}$ Electrochemical Society Meeting, Seattle, May 1999.

2. J.K. Hong, L.A. Zook, M. Inbodý, J. Tafoya and N.E. Vanderborgh, Abstract No.570 in Meeting Abstracts of $195^{\text {th }}$ Electrochemical Society Meeting, Seattle, May 1999.

3. K.B. Prater, J Power Sources, 51, 129 (1994).

4. S. Gottesfeld, in Advances in Electrochemical Science and Engineering, C. Tobias et 
al. eds., 5, 195, John Wiley and Sons, New York (1997).

5. D. M. Bernardi, and M. W. Verbrugge, AIChE J., 37, 1151 (1991).

6. D. M. Bernardi, and M. W. Verbrugge, J. Electrochem. Soc., 139, 2477 (1992).

7. T. E. Springer, T. A. Zawodinski, and S. Gottesfeld, J. Electrochem. Soc., 136, 2334 (1991).

8. T.E. Springer, M.S. Wilson and S. Gottesfeld, J. Electrochem. Soc., 140, 3513 (1993).

9. T.F. Fuller and J. Newman, J. Electrochem Soc, 140, 1218 (1993).

10. T.V. Nguyen and R.E. White, J. Electrochem. Soc., 140, 2178 (1993).

11. V. Gurau, H. Liu, and S. Kạkac, AIChE J., 44, 2410 (1998).

12. J. S. Yi and T. V. Nguyen, J. Electrochem. Soc., 145, 1149 (1998).

13. J. S. Yi and T. V. Nguyen, J. Electrochem. Soc., 146, 38 (1999).

14. T.V. Nguyen, presented at $195^{\text {th }}$ Mtg. of Electrochemical Society, May 4-7, Seattle (1999).

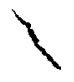

15. C.Y. Wang, Z.H. Wang and Y. Pan, in Proc. of IMECE99, ASME, New York (1999).

16. W.B. Gu, C.Y. Wang and B.Y. Liaw, J. Electrochem Soc, 144, 2053 (1997).

17. W.B. Gu, C.Y. Wang and B.Y. Liaw, J. Power Sources, 75/1, 154 (1998).

18. W.B. Gu, C.Y. Wang and B.Y. Liaw, J. Electrochem Soc, 145, 3418 (1998).

19. C. Y. Wang, W. B. Gu, and B.Y. Liaw, J. Electrochem. Soc., 145, 3407 (1998).

20. C.Y. Wang, W.B. Gu, R. Cullion and B. Thomas, in Proc. of IMECE99, ASME, New York (1999).

21. W.B. Gu, C.Y. Wang, S. Li, M.M. Geng and B.Y. Liaw, Electrochem. Acta, 44, 4525 (1999).

22. W.B. Gu, C.Y. Wang, J. Weidner, R. Jungst and G. Nagasubramanian, J. Electro- 
chem. Soc., accepted for publication (1999).

23. E. A. Ticianelli, C. R. Derouin, and S. Srinivasan, J. Electroanal. Chem., 251, 275 (1988).

24. A. Parthasarathy, S. Srinivasan, and A. J. Appleby, J. Electrochem Soc, 139, 2530 (1992).

25. R. B. Bird, W.E. Stewart and E.N. Lightfoot, Transport Phenomena, John Wiley \& Sons, Inc., New York (1960).

26. S. V. Patankar, Numerical Heat Transfer and Fluid Flow, Hemisphere, New York (1980). 1

27. V.R. Voller, Numer. Heat Transfer, Part B, 17, 155 (1990). 
Table I. Source terms for momentum, species and charge conservation equations in various region.

\begin{tabular}{c|c|c|c}
\hline & $S_{u}^{\prime}$ & $S_{k}$ & $S_{\Phi}$ \\
\hline $\begin{array}{c}\text { Gas Channels } \\
\begin{array}{c}\text { Diffusion } \\
\text { Electrodes }\end{array}\end{array}$ & 0 & 0 & N/A \\
\hline $\begin{array}{c}\text { Catalyst } \\
\text { Layers }\end{array}$ & $-\frac{\mu}{K} \varepsilon^{2} \vec{u}$ & 0 & 0 \\
$k_{p} \varepsilon_{m} \varepsilon_{m c} \vec{u}+\frac{k_{\Phi}}{k_{p}} z_{f} c_{f} F \nabla \Phi_{e}$ & $\frac{j_{c}}{4 F c_{\text {totc }}}$ for $\mathrm{O}_{2}$ & $j$ \\
\hline Membrane & $-\frac{\mu}{k_{p}} \varepsilon_{m} \vec{u}+\frac{k_{\Phi}}{k_{p}} z_{f} c_{f} F \nabla \Phi_{e}$ & $-\frac{j_{u}}{2 F c_{\text {tota }}}$ for $\mathrm{H}_{2} \mathrm{O}$ & \\
\hline
\end{tabular}


Table II. Physical Parameters and Properties at 353K

$$
\text { Quantity }
$$

Gas channel length

Gas channel width

Gas diffuser width

Catalyst layer width

Membrane width

Fixed charge concentration, $c_{f}$

Oxygen diffusivity in gas

Hydrogen diffusivity in gas

Dissolved oxygen diffusivity in active layer and membrane

Dissolved hydrogen diffusivity in active layer and membrane

Faraday constant, $F$

Hydraulic permeability of membrane, $k_{p}$

Permeability of gas diffuser, $K$

Electrokinetic permeability, $k_{\Phi}$

Universal gas constant, $R$

Fixed site charge, $z_{f}$

Cathodic transfer coeff., $\alpha_{c}$

Anodic transfer coeff., $\alpha_{u}$

Gas diffuser porosity, $\varepsilon$

Membrane water porosity, $\varepsilon_{m}$

Volume fraction membrane in catalyst layer, $\varepsilon_{m c}$

Inlet nitrogen-oxygen mole ratio, $X_{N 2} / X_{O 2}$

Air-side inlet pressure/fuel-side inlet pressure

$\mathrm{O}_{2}$ stoichiometric flow ratio, $\zeta_{+}$

$\mathrm{H}_{2}$ stoichiometric flow ratio, $\zeta$.

Relative humidity of inlet air/fuel (anode/cathode)

Ref. exch. current density $\mathrm{x}$ area of anode, $a j_{0-}^{\text {ref }}$

Ref. exch. current density $x$ area of cathode, $a j_{0_{+}}^{\text {ref }}$

Total mole concentration at the anode side, $c_{\text {tuta }}$

Total mole concentration at the cathode side, $c_{\text {torc }}$

Value at $353 \mathrm{~K}$

$7.112 \mathrm{~cm}$

$0.0762 \mathrm{~cm}$

$0.0254 \mathrm{~cm}$

$0.00287 \mathrm{~cm}$

$0.023 \mathrm{~cm}$

$1.2 \times 10^{3} \mathrm{~mol} / \mathrm{m}^{3}$

$5.2197 \times 10^{-6} \mathrm{~m}^{2} / \mathrm{s}$

$2.63 \times 10^{-10} \mathrm{~m}^{2} / \mathrm{s}$

$1.22 \cdot 10^{-10} \dot{m}^{2} / s$

$2.59 \cdot 10^{-10} \mathrm{~m}^{2} / \mathrm{s}$

$96487 \mathrm{C} / \mathrm{mol}$

$1.8 \cdot 10^{-18} \mathrm{~m}^{2}$

$1.76 \cdot 10^{-11} \mathrm{~m}^{2}$

$7.18 \cdot 10^{-20} \mathrm{~m}^{2}$

$8314 \mathrm{~J} / \mathrm{mol} \cdot \mathrm{K}$

$-1$

2

2
0.4

0.28

0.4

$0.79 / 0.21$

$5 / 3$ atm

3.0

1.3

$100 / 0 \%$

5. $\times 10^{8} \mathrm{~A} / \mathrm{m}^{3}$

- $0.5 \mathrm{~A} / \mathrm{m}^{3}$

$66.817 \mathrm{~mol} / \mathrm{m}^{3}$

$17.808 \mathrm{~mol}^{-\mathrm{m}^{3}}$ 


\section{List of Figures}

Figure 1. Schematic diagram of a proton-exchange-membrane (PEM) fuel cell.

Figure 2. Comparison of predicted and measured cell polarization curves at two operating temperatures. The experimental data were taken from Ticianelli et al. (1988).

Figure 3. (a) Computed velocity profiles in anode and cathode flow channels, (b) water vapor mole fraction and (c) oxygen mole fraction in the cathode gas diffuser and flow channel for $I_{\text {arg }}=8297 \mathrm{~A} / \mathrm{m}^{2}, X_{H 20 .+^{+}}^{0}=0$, and $T=353 \mathrm{~K}$. The left boundary in (b) and (c) is the interface between catalyst layer and gas-diffusion cathode.

Figure 4. Local current density distributions in the axial distance ( $y$-direction) for $X_{H 20 .+}^{0}=0$ and $T=353 \mathrm{~K}$.

Figure 5. Water mole fraction profiles along the interface between the cathode catalyst layer and gas diffuser for $X_{H 2 \dot{0 .+}}^{0}=0$ and $T=353 \mathrm{~K}$.

Figure 6. Hydrogen dilution effect on the cell average current density for $X_{H 20 .+}^{0}=0$, $V_{\text {cell }}=0.6 \mathrm{~V}$ and $T=353 \mathrm{~K}$.

Figure 7. Effect of the inlet hydrogen mole fraction on cell polarization curves for $X_{H 20 .+}^{0}=0$ and $T=353 \mathrm{~K}$.

Figure 8. Phase potential distributions in the transverse direction ( $x$-direction) for $V_{\text {cell }}=0.6 \mathrm{~V}, X_{H 20 .+}^{0}=0, T=353 \mathrm{~K}$, and $\zeta_{-}=2.8$ at $1 \mathrm{~A} / \mathrm{cm}^{2}$ for Pure $\mathrm{H}_{2}$.

Figure 9. Hydrogen mole fraction distributions in the anode flow channel and gas diffusion electrode for $X_{H 2 O,+}^{0}=0, V_{\text {cell }}=0.6 \mathrm{~V}, T=353 \mathrm{~K}$, and $\zeta_{-}=2.8$ at $1 \mathrm{~A} / \mathrm{cm}^{2}$ :

(a) $10 \%$ hydrogen $\left(X_{H 2,-}^{0}=0.08441\right)$ and (b) pure hydrogen $\left(X_{H 2,-}^{0}=0.8441\right)$.

Figure 10. Hydrogen mole fraction profiles at: (a) the flow channel wall, (b) the interface between the anode flow channel and gas diffusion electrode, and (c) the interface between the gas diffusion anode and catalyst layer for $X_{H 2 O .+}^{0}=0, V_{\text {cell }}=0.6 \mathrm{~V}$, and $T=353 \mathrm{~K}$. 


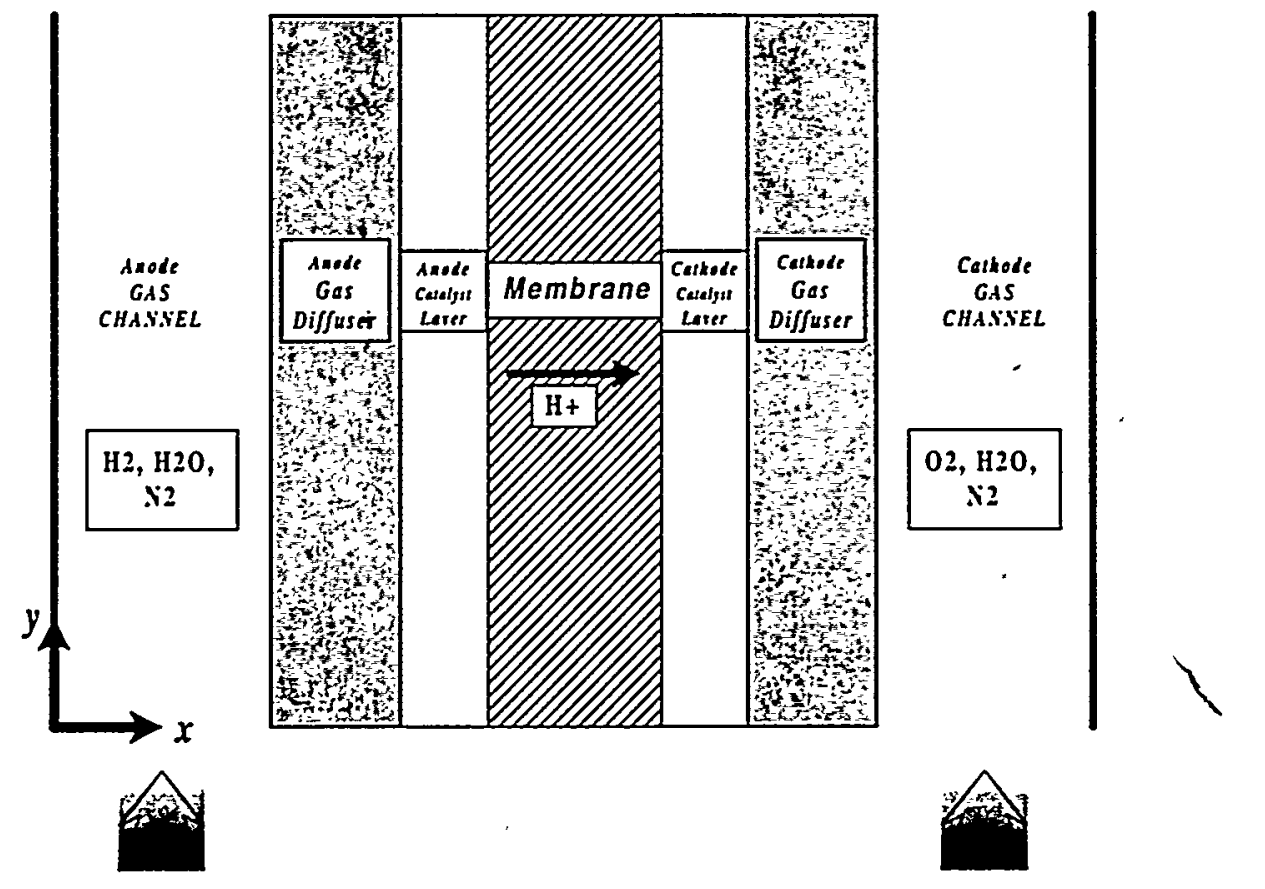

Figure 1. Schematic diagram of a proton-exchange-membrane (PEM) fuel cell. 

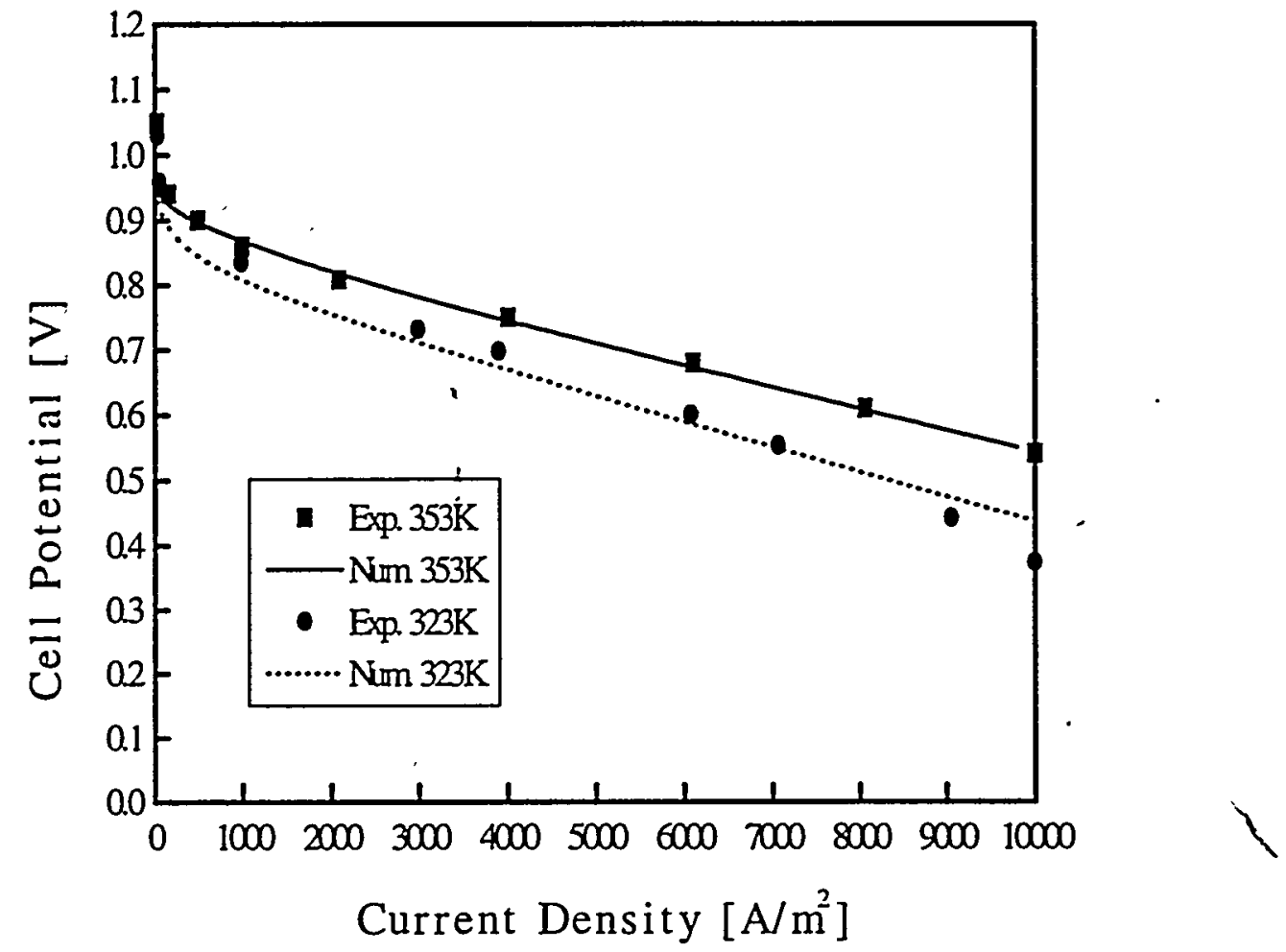

Figure 2. Comparison of predicted and measured cell polarization curves at two operating temperatures. The experimental data were taken from Ticianelli et al. (1988). 


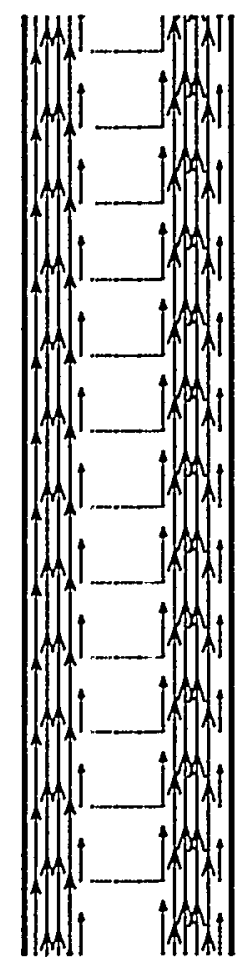

(a)

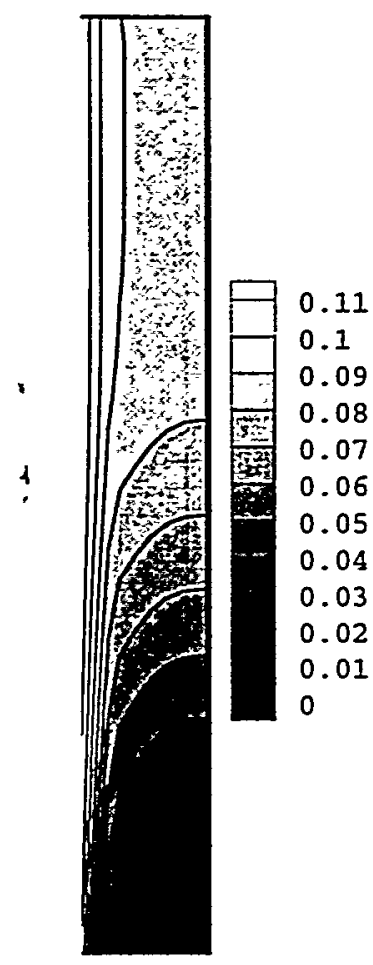

(b)

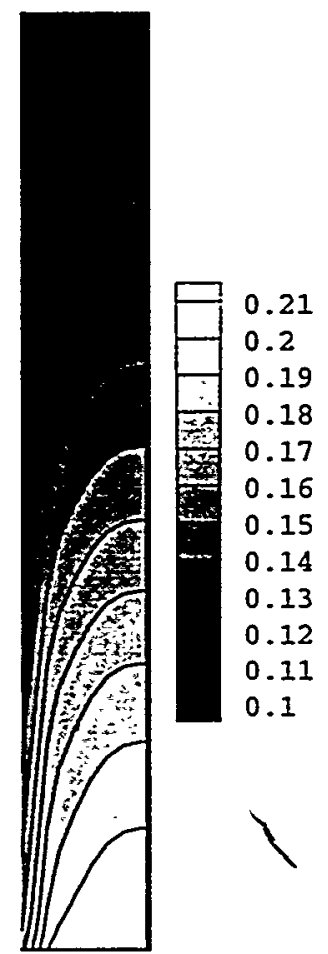

(c)

Figure 3. (a) Computed velocity profiles in anode and cathode flow channels, (b) water vapor mole fraction and (c) oxygen mole fraction (c) in the cathode gas diffuser and flow channel for $I_{\text {arg }}=8297 \mathrm{~A} / \mathrm{m}^{2}, X_{H 20,+}^{0}=0$, and $T=353 \mathrm{~K}$. The left boundary in (b) and (c) is the interface between catalyst layer and gas-diffusion cathode. 


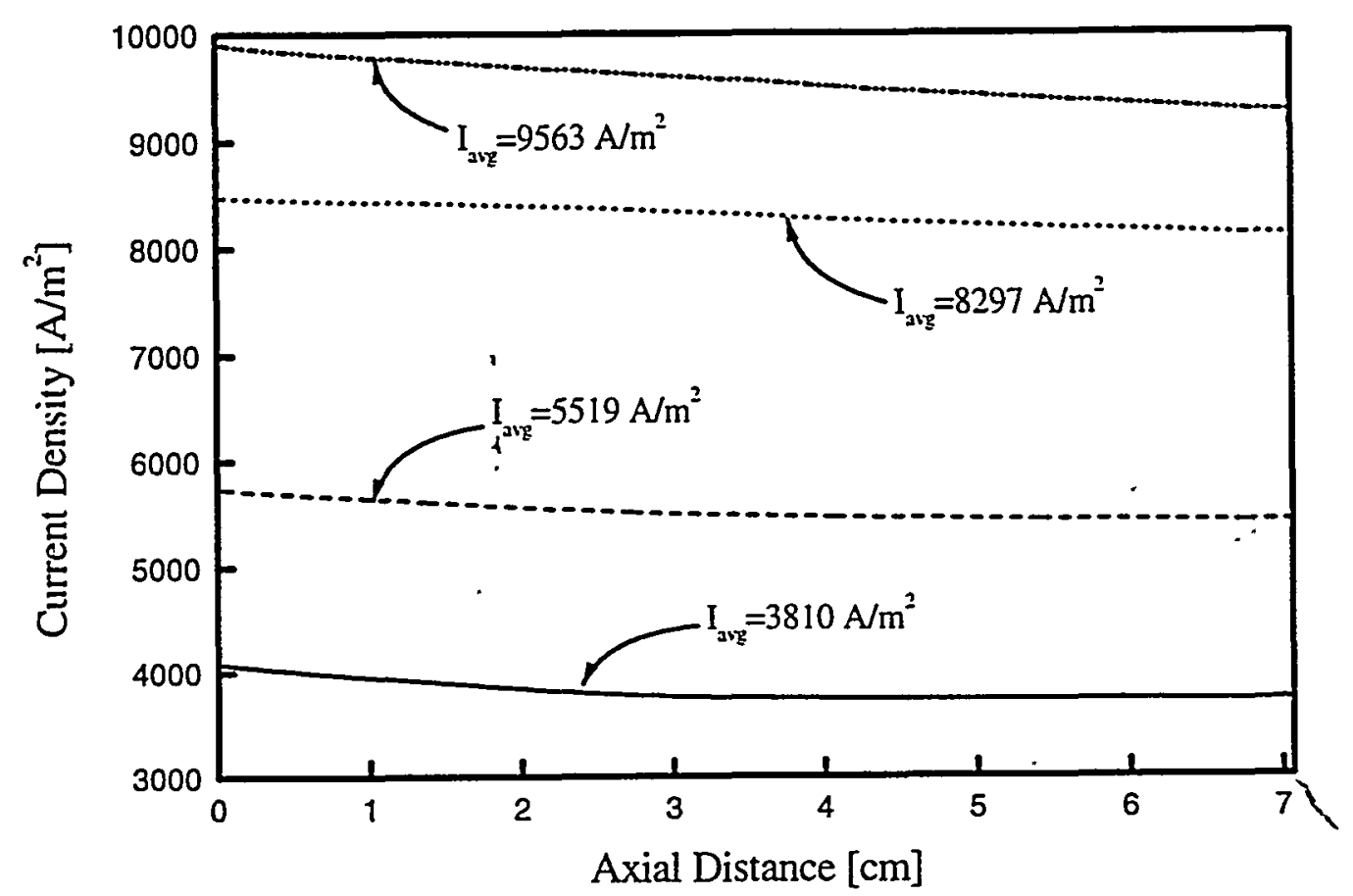

Figure 4. Local current density distributions in the axial distance (y-direction) for $X_{H 20 .+}^{0}=0$ and $T=353 \mathrm{~K}$. 


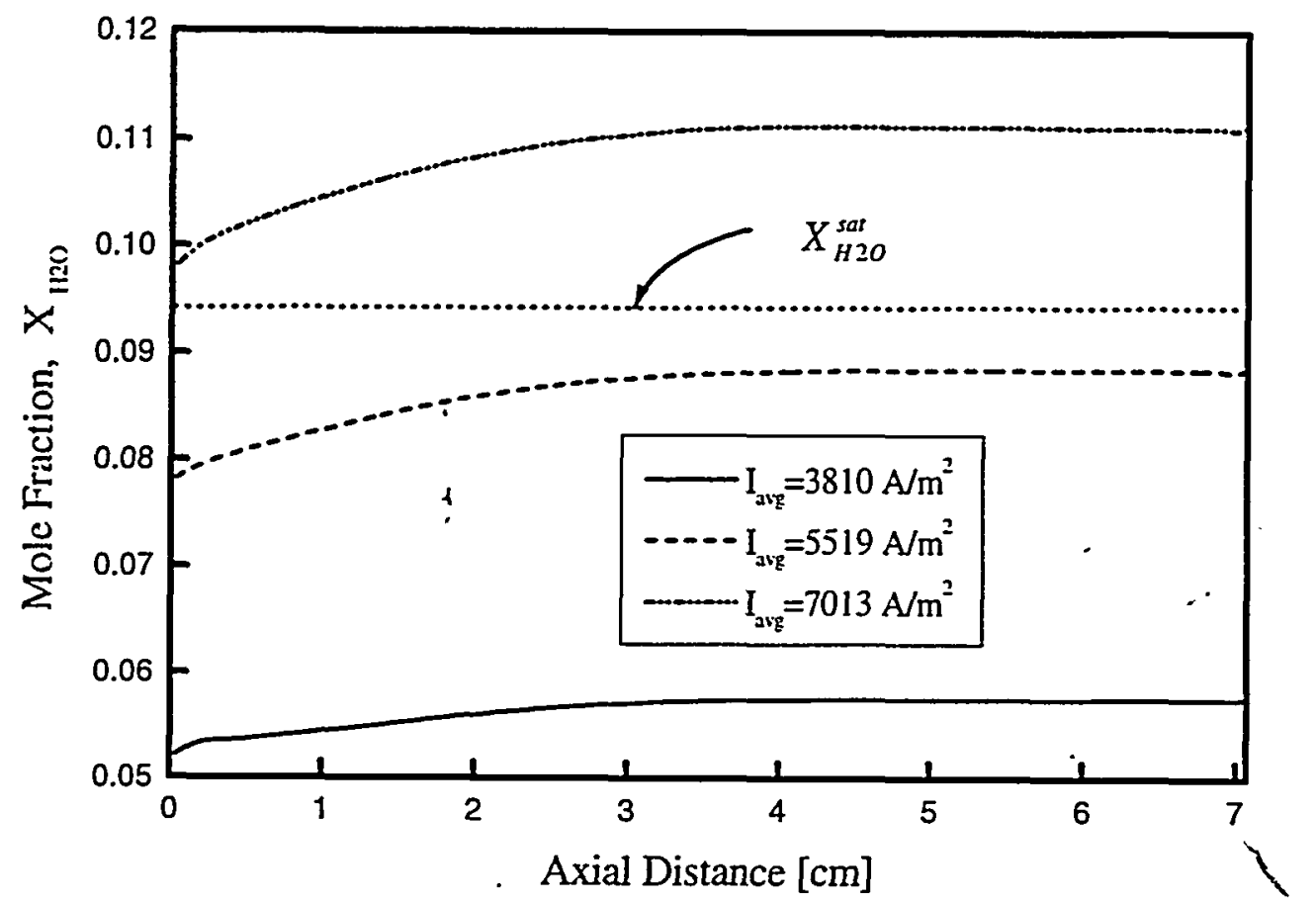

Figure 5. Water mole fraction profiles along the interface between the cathode catalyst layer and gas diffuser for $X_{H 2 O .+}^{0}=0$ and $T=353 \mathrm{~K}$. 


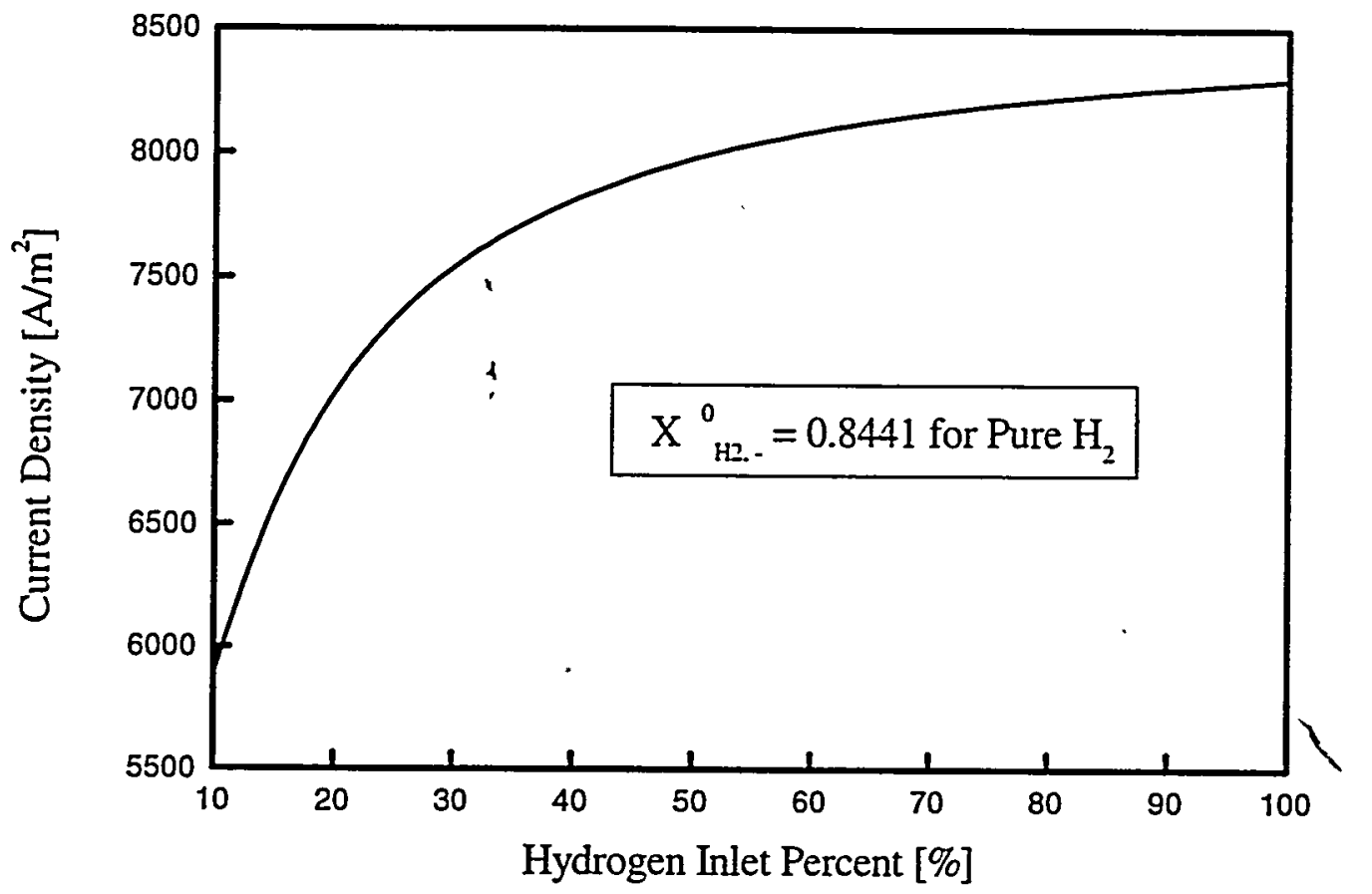

Figure 6. Hydrogen dilution effect on the cell average current density for $X_{H 2 O,+}^{0}=0$, $V_{\text {cell }}=0.6 \mathrm{~V}$ and $T=353 \mathrm{~K}$. 


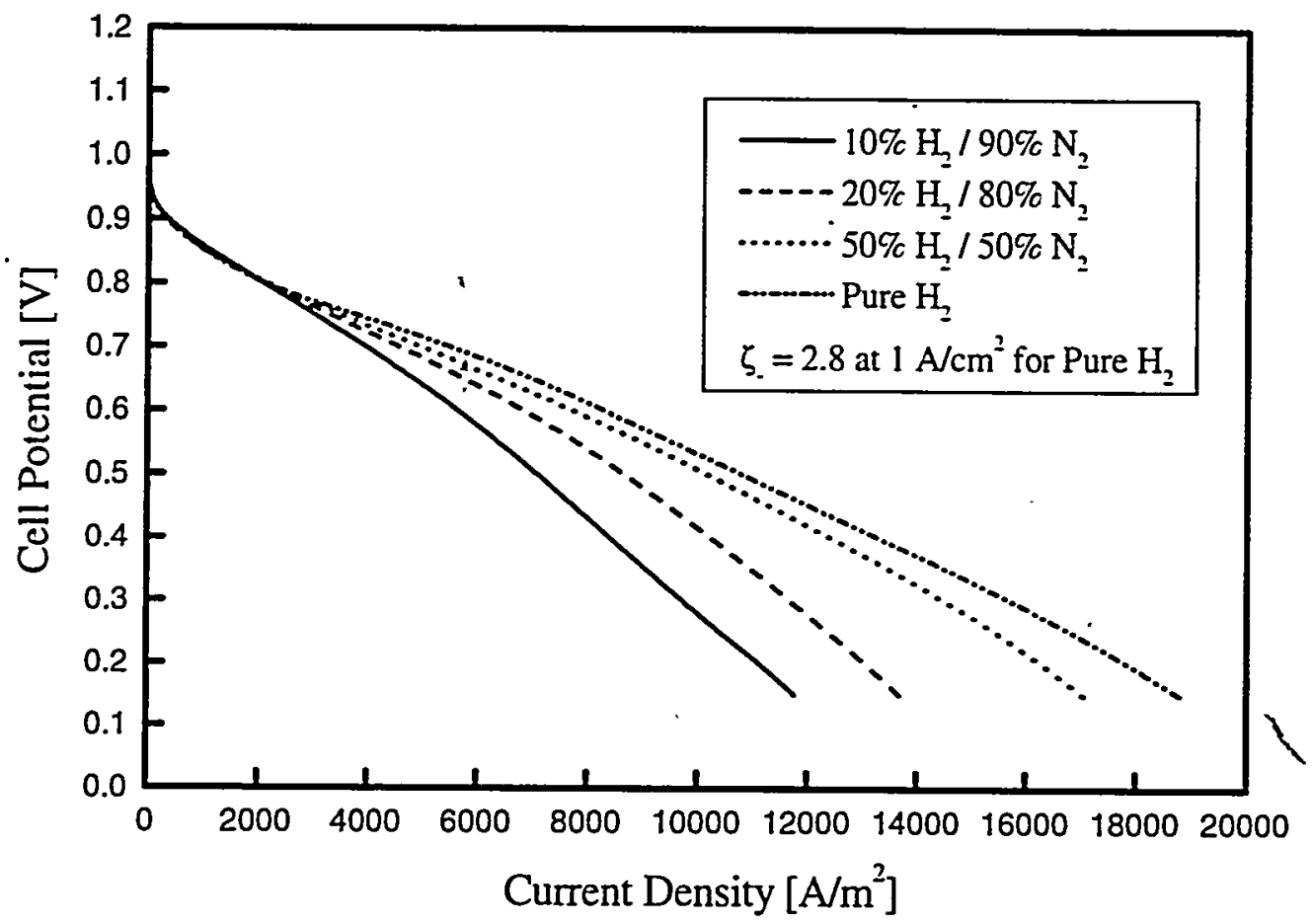

Figure 7. Effect of the inlet hydrogen mole fraction on cell polarization curves for $X_{H 2 O_{.+}}^{0}=0$ and $T=353 \mathrm{~K}$. 


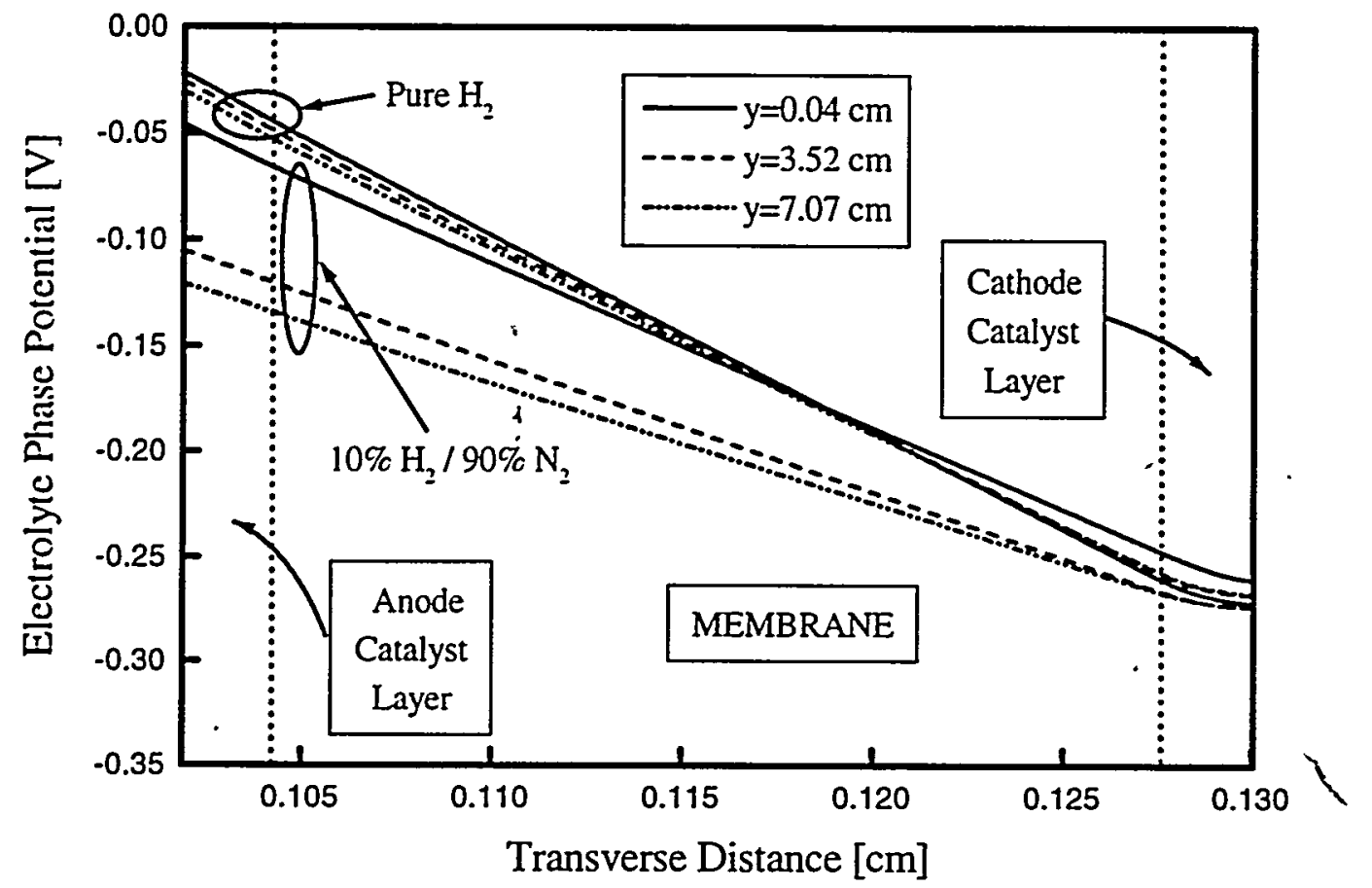

Figure 8. Phase potential distributions in the transverse direction ( $x$-direction) for $V_{\text {cell }}=0.6 \mathrm{~V}, X_{H 2 O .+}^{0}=0, T=353 \mathrm{~K}$, and $\zeta_{-}=2.8$ at $1 \mathrm{~A} / \mathrm{cm}^{2}$ for Pure $\mathrm{H}_{2}$. 


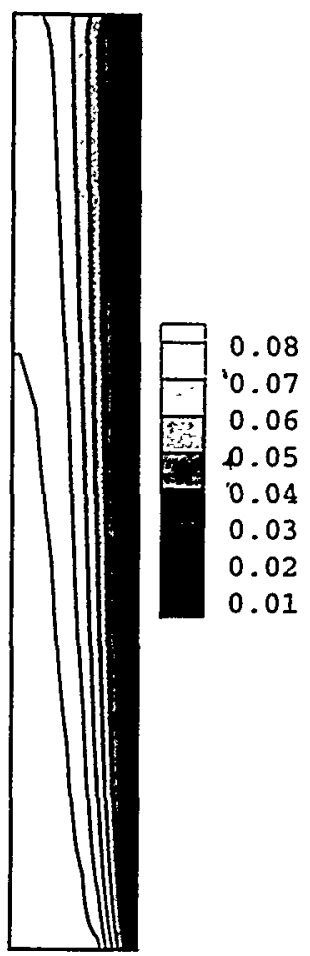

(a)

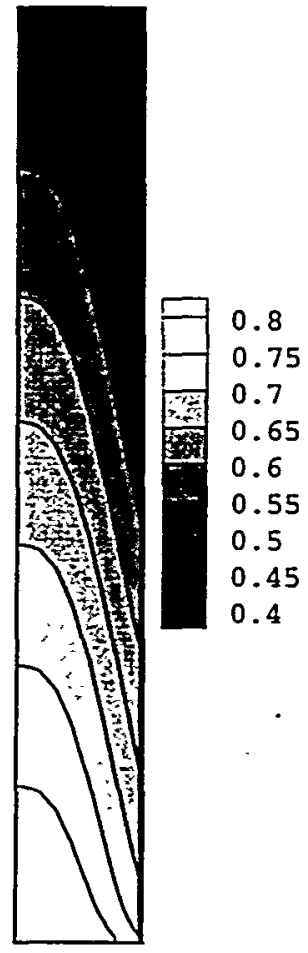

(b)

Figure 9. Hydrogen mole fraction distributions in the anode flow channel and gas diffusion electrode for $X_{H 2 O_{.+}}^{0}=0, V_{\text {cell }}=0.6 \mathrm{~V}, T=353 \mathrm{~K}$, and $\zeta_{-}=2.8$ at $1 \mathrm{Alcm}^{2}$ : (a) $10 \%$ hydrogen $\left(X_{H 2,-}^{0}=0.08441\right)$ and (b) pure hydrogen $\left(X_{H 2,-}^{0}=0.8441\right)$. 


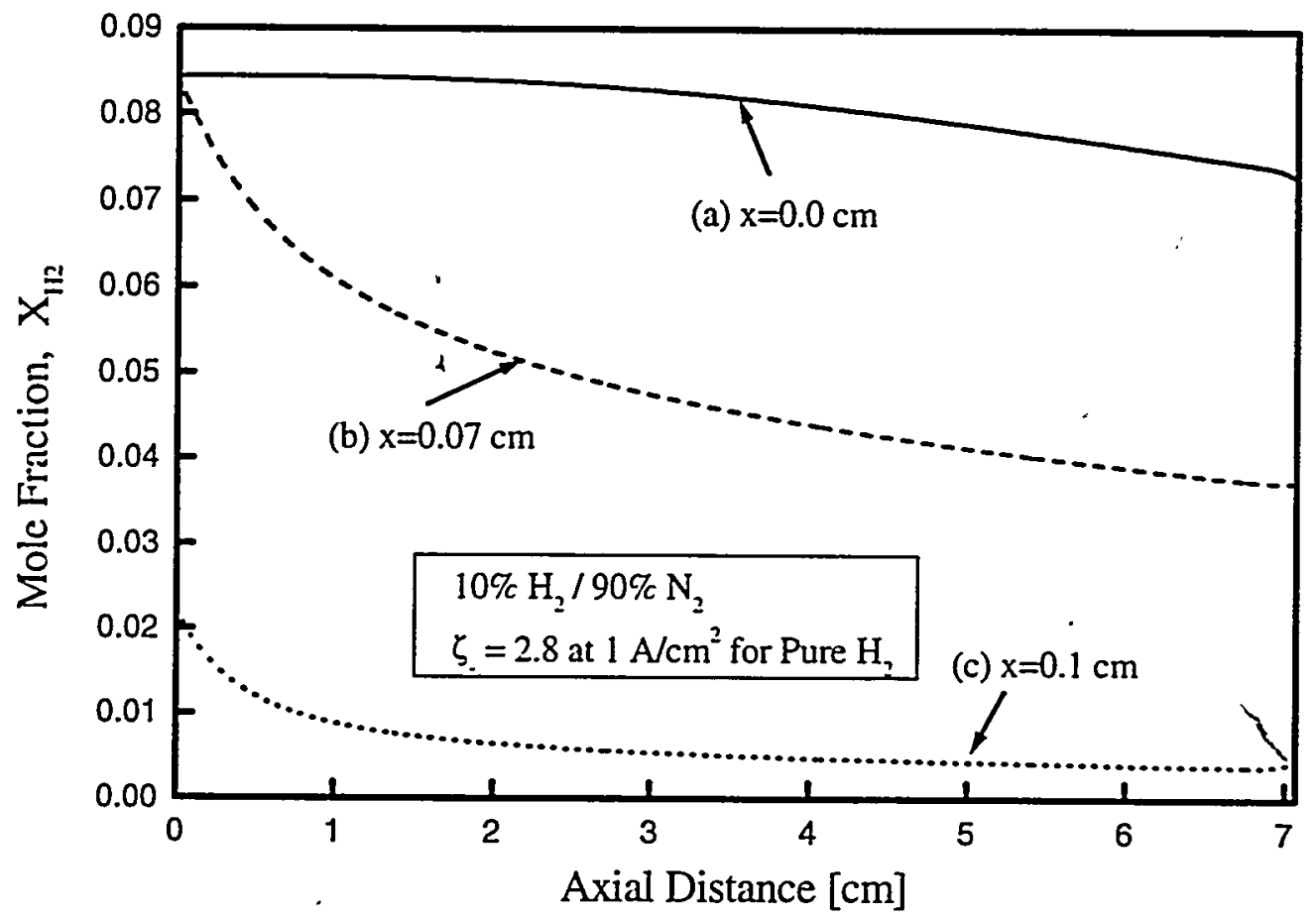

Figure 10. Hydrogen mole fraction profiles at: (a) the flow channel wall, (b) the interface between the anode flow channel and gas diffusion electrode, and (c) the interface between the gas diffusion anode and catalyst layer for $X_{H 2 O .+}^{0}=0, V_{\text {cell }}=0.6 \mathrm{~V}$, and $T=353 K$. 